\title{
Does Dose Volume Histogram of Parotid Glands Correlate with Xerostomia Radiation Therapy Oncology Group Scores in Locoregionally Advanced Head and Neck Cancer Patients Treated with Intensity-Modulated Radiation Therapy?
}

\author{
Sajal Goel ${ }^{1}$ Ritu Bhutani ${ }^{1}$ Vivek Bansal ${ }^{1} \quad$ Ruchika Goel ${ }^{2}$
}

${ }^{1}$ Department of Radiation Oncology, Rajiv Gandhi Cancer Institute and Research Center, New Delhi, India

2Department of Quality, Rajiv Gandhi Cancer Institute and Research Center, New Delhi, India

Asian J Oncol 2021;7:118-125.

\begin{abstract}
Address for correspondence Sajal Goel, DNB, Department of Radiation Oncology, Rajiv Gandhi Cancer Institute and Research Center, Sir Chotu Ram Marg, Sector 5, Rohini, New Delhi 110085, India (e-mail: drsajal.goel@gmail.com).
\end{abstract}

\author{
Abstract \\ Keywords \\ - dose volume \\ histogram \\ - ICRU 62 \\ - IMRT \\ - locoregionally \\ advanced head and \\ neck cancer \\ - subjective xerostomia
}

Introduction Xerostomia is an imminent complication of head and neck radiotherapy best assessed subjectively. This study aimed to evaluate the effects of sparing parotid glands with intensity-modulated radiation therapy (IMRT) on subjective xerostomia scores in patients with locoregionally advanced head and neck cancer.

Subjects and Methods This is a prospective longitudinal study conducted in an outpatient department setting. A total of 43 patients with head and neck cancer were planned with IMRT as per the ICRU 62 (International Commission on Radiation Units and Measurement Report 62). The constraints to ipsilateral and contralateral parotid glands were 35 and 25 Gy, respectively. Treatment plan was assessed for doses to $100,67,50$, and $33 \%$ volume of individual parotid glands. Patients were subjectively assessed using the Amosson's Questionnaire and graded as per Eisbruch's xerostomia Radiation Therapy Oncology Group scores. Dose volume histogram (DVH) was plotted and correlated with grades of xerostomia postradiation at 1, 3, 6, 9 and 12 months follow-ups. Statistical analysis was performed suing SPSS version 16, chi-square test, and one-way analysis of variance test.

Results No statistically significant correlation between mean dose of radiation, volume of the parotid glands, and grades of xerostomia was noted postradiation. A statistically significant improvement in grades of xerostomia between 3 and 6 months $(p=0.0), 3$ and 9 months $(p=0.020), 6$ and 9 months $(p=0.009), 6$ and 12 months $(p=0.05)$, and 9 and 12 months $(p=0.00)$ was noted. Recovery in grades was noted at 9 months.

Conclusion There is no statistically significant direct correlation between DVH of the parotid glands and grades of xerostomia, although recovery in grades was statistically significant at 9 months. published online November 8, 2020
DOI https://doi.org/ $10.1055 / \mathrm{s}-0040-1718978$ ISSN 2454-6798.
๑ 2020. Spring Hope Cancer Foundation \& Young Oncologist Group of Asia.

This is an open access article published by Thieme under the terms of the Creative Commons Attribution-NonDerivative-NonCommercial-License, permitting copying and reproduction so long as the original work is given appropriate credit. Contents may not be used for commercial purposes, or adapted, remixed, transformed or built upon. (https://creativecommons.org/licenses/by-nc-nd/4.0/) Thieme Medical and Scientific Publishers Pvt. Ltd., A-12, 2nd Floor, Sector 2, Noida-201301 UP, India 


\section{Introduction}

Xerostomia is one of the most common complications of radiotherapy (RT) in patients with head and neck cancer. Xerostomia can be assessed both objectively by cannulation of ducts and subjectively with questionnaire. Subjective xerostomia does not reach a steady state even more than 5 years after RT and thus continues to influence a patient's quality of life (QOL). ${ }^{1-8}$ Various studies have shown that patient-reported end points are more indicative of its true effect.9-13

It is a well-established fact that dosimetric and volumetric sparing of the parotid glands improves subjective xerostomia. In this regard, a parotid gland mean dose of $\leq 26 \mathrm{~Gy}$ should be the planning goal if functional recovery of the parotid gland is desired..$^{14}$ However, we would have to introspect if this was truly achievable even in patients with locoregionally advanced head and neck cancer.

This study was conducted at a tertiary cancer center in India with a primary objective to correlate dose volume histogram (DVH) of the parotid glands with xerostomia Radiation Therapy Oncology Group (RTOG) scores in locoregionally advanced head and neck cancer patients treated with intensity-modulated radiation therapy (IMRT). The secondary objectives were to compare various subjective xerostomia scores obtained postradiation with preradiation values and to study the time trends of xerostomia.

\section{Subjects and Methods}

\section{Patient Selection}

The study was conducted between November 2008 and September 2009. A total of 43 patients with locoregionally advanced head and neck cancer (definitive and postoperative) were randomly included in the study after they signed written consent form (RGCI Ethics Committee ID: 186/RO/ VKB). The inclusion criteria were age $>18$ years, either sex with Karnofsky index $>70$ and squamous cell carcinomas, and those who required bilateral comprehensive irradiation to the neck if the standard field arrangements were used. The exclusion criteria were salivary gland dysfunction and a past history of trauma, malignancy, or radiation.

\section{External Beam Radiation Planning}

The patient was immobilized in an Orfit cast. An axial contrast-enhanced computed tomography (CT) scan extending craniocaudally from the vertex to the fourth dorsal vertebrae at $5-\mathrm{mm}$ intervals was performed. The volumes were contoured as per the International Commission on Radiation Units and Measurement Report 62 guidelines. Delineation of gross tumor volume (GTV) was performed as per clinical findings and radiological imaging. Clinical target volume (CTV) was delineated as a high-risk volume, with a margin of $1.5 \mathrm{~cm}$ around the GTV, respecting the anatomical barrier. Planning target volume (PTV) was drawn with a margin of $3 \mathrm{~mm}$ around CTV. Low-risk CTV was defined as the low-risk volume and included uninvolved neck node levels selected on the basis of primary site and status of the neck. For the nodal levels, we followed our in house protocol based on the guidelines described by Eisbruch et al and Grégoire et al. ${ }^{14,15}$ Wherever required, two or three levels of contouring were performed.

\section{Dose Prescription}

The prescription dose to CTV ranged from $66 \mathrm{~Gy}$ to $70 \mathrm{~Gy}$ in 30 to 35 fractions (2 Gy per fraction). The ipsilateral $(\mathrm{I} / \mathrm{L})$ high-risk nodal region was prescribed a dose $60 \mathrm{~Gy}$ (1.7-1.8 Gy per fraction), whereas the contralateral $(\mathrm{C} / \mathrm{L})$ low-risk nodal region prescribed a dose of 54 to $56 \mathrm{~Gy}$ (1.63-1.69 Gy per fraction). In the postoperative patients, the prescribed dose ranged from 56 to $60 \mathrm{~Gy}$ to the CTV in 28 to 30 fractions ( 2 Gy per fraction), with low-risk nodal region receiving a dose of 52 to $54 \mathrm{~Gy}$. The prescription dose was the dose covering $95 \%$ of PTV. All normal structures including parotid glands were delineated, and dose constraints were given. The constraints to I/L and C/L parotid glands were set at 35 and $25 \mathrm{~Gy}$, respectively, as described by Amosson et al. ${ }^{16}$ If dose constraints could not be met for both parotids, only the C/L parotid was spared. The IMRT plans were generated, and doses received by tumor and surrounding normal organs such as parotid, spinal cord, and oral cavity were calculated.

\section{Treatment Delivery and Patient Assessment}

The external beam radiation treatment to face and neck was delivered in PRIMUS Linear Accelerator (Siemens Medical Systems, Inc., Concord, NH). Patients also received concurrent chemotherapy with intravenous cisplatin $35 \mathrm{mg} / \mathrm{m}^{2}$ every week or biotherapy with intravenous cetuximab $400 \mathrm{mg} / \mathrm{m}^{2}$ loading dose and $200 \mathrm{mg} / \mathrm{m}^{2}$ every week was given if indicated. The patients were interviewed subjectively as per Amosson's Questionnaire, and responses were scored as per Eisbruch's xerostomia RTOG scores (- Tables 1, 2). ${ }^{16,17}$ Assessment of xerostomia was performed before starting IMRT, and at 1, 3, 6, 9, and 12 months postradiation. Patients were also evaluated for any treatment-related acute, subacute, and chronic morbidity.

Table 1 Questionnaire for the assessment of xerostomia ${ }^{16}$

\begin{tabular}{|l|l|}
\hline \multicolumn{2}{|c|}{ Amosson's subjective questionnaire for assessment of } \\
xerostomia
\end{tabular}


Table 2 Eisbruch's grading for xerostomia ${ }^{17}$

\begin{tabular}{|l|l|}
\hline \multicolumn{2}{|c|}{ Eisbruch's grading for xerostomia } \\
\hline Grade 1 & No disability \\
\hline Grade 2 & Dryness requiring additional fluids for swallowing \\
\hline Grade 3 & $\begin{array}{l}\text { Dryness causing dietary alterations, interference with } \\
\text { sleep, speaking, or other activities }\end{array}$ \\
\hline
\end{tabular}

\section{Data Analysis}

The data were analyzed using SPSS software Version 16 (IBM Corp.). DVH was correlated with xerostomia scores using the chi-square test. The patients were divided into three subgroups receiving mean doses of $<30,30$ to 40 , and $>40$ Gy to parotids. One-way analysis of variance test analyzed the data pertaining to the volume of the parotid glands irradiated, dose received by parotid glands, and the grades of xerostomia. The data were also analyzed for time trends in xerostomia. The threshold for statistical significance was a $p$-value of 0.05 .

\section{Results}

In this study, the oral cavity was the commonest subsite followed by oropharynx and hypopharynx. All patients had squamous cell carcinomas except one with sinonasal lymphoepithelioma. Around 51\% patients in the whole group presented with T1/T2 lesion, and 20.9\% patients each presented with T3/T4 lesions and nodal mass with unknown primary. Most of them had locally advanced disease, with stage III and IV seen in $81.4 \%$ cases. The dose to 95\% PTV ranged from 55 to $69.9 \mathrm{~Gy}$, with the mean dose being $61.5 \mathrm{~Gy}$. The pattern of lymph nodes showed N3 disease in 2.3\% patient, $\mathrm{N} 2$ in $46.5 \%$, and $\mathrm{N} 1$ in $27.9 \%$ patients. The most common lymph nodes were upper deep cervical group (- Table 3 ). The mean doses to I/L and C/L nodal CTV 95 in the definitive radiation group were 60.8 and $58.5 \mathrm{~Gy}$, respectively (-Fig. 1). The mean doses to I/L and C/L nodal CTV 95 in the postoperative group were 57.5 and $55 \mathrm{~Gy}$, respectively (-Fig. 1).

The mean doses achieved by $\mathrm{I} / \mathrm{L}$ and $\mathrm{C} / \mathrm{L}$ parotid gland were 36.5 Gy (range: 9.0-62.9 Gy) and 28.3 Gy (range: 6.7-39.6 Gy), respectively (-Fig. 2). The average volume of the parotid gland above the threshold value (35 Gy for the $\mathrm{I} / \mathrm{L}$ parotid gland and $25 \mathrm{~Gy}$ for the $\mathrm{C} / \mathrm{L}$ parotid gland) as determined from DVH was $21.1 \mathrm{~mL}$ in the $\mathrm{I} / \mathrm{L}$ parotid gland and $23.5 \mathrm{~mL}$ in the $\mathrm{C} / \mathrm{L}$ parotid gland (-Figs. 2 ).

No statistically significant direct correlation between mean dose and grades of xerostomia was noted postradiation at 1 month ( $p=0.500$ for $\mathrm{I} / \mathrm{L}$ and 0.450 for $\mathrm{C} / \mathrm{L}$ ), 3 months ( $p=0.455$ for $\mathrm{I} / \mathrm{L} 0.509$ for $\mathrm{C} / \mathrm{L}), 6$ months $(p=0.762$ for $\mathrm{I} / \mathrm{L}$ and 0.461 for $\mathrm{C} / \mathrm{L}$ ), 9 months $(p=0.674$ for $\mathrm{I} / \mathrm{L}$ and 0.713 for $\mathrm{C} / \mathrm{L}$ ), and 12 months ( $p=0.225$ for $\mathrm{I} / \mathrm{L}$ and 0.423 for $\mathrm{C} / \mathrm{L}$ ). No direct statistical correlation was seen between the grades of xerostomia and the volume of the parotid glands at 3 months ( $p=0.343$ for $\mathrm{I} / \mathrm{L}$ and 0.862 for $\mathrm{C} / \mathrm{L}), 6$ months $(p=0.271$ for $\mathrm{I} / \mathrm{L}$ and 0.892 for $\mathrm{C} / \mathrm{L}), 9$ months $(p=0.438$ for $\mathrm{I} / \mathrm{L}$ and 0.773 for $\mathrm{C} / \mathrm{L}$ ), and 12 months ( $p=0.503$ for $\mathrm{I} / \mathrm{L}$ and 0.523 for $\mathrm{C} / \mathrm{L}$ ) (-Table 4). The percentage of patients with xerostomia grade 2 or more at various months of follow-up is shown in - Table 5.
Recovery in the grades of xerostomia was assessed at 3-month interval after completion of RT. A statistically significant improvement was seen between grades of xerostomia at 3 and 6 months $(p=0.00), 3$ and 9 months $(p=0.020), 6$ and 9 months $(p=0.009), 6$ and 12 months $(p=0.05)$, and 9 and 12 months $(p=0.00)$. The time trends of grade 3 xerostomia revealed a static phase from 6 to 9 months, whereas a decrease was seen between 3 to 6 months and 9 to 12 months, with the slope of this downfall more than that at 3 months (-Fig. 3). Thus, significant recovery was noticed at 9 months.

Concurrent chemotherapy was delivered to $74.4 \%$ patients in the form of cisplatin and cetuximab. Eleven patients received RT alone. Minor deviation in the treatment protocol was seen in two patients who received neoadjuvant chemotherapy before chemoradiation.

All patients except one were able to complete their treatment as defined in the protocol. In the whole group, one patient was lost to follow-up after completing 25 fractions of treatment, and one patient refused for participation in the study after 3 months; overall, five patients were lost to follow-up. The median follow-up of the study was 15 months.

\section{Discussion}

In this study, more than $80 \%$ of patients had a locoregionally advanced disease. The two radiobiological concepts of IMRT using accelerated fractionation with simultaneous integrated boost and conformal avoidance were utilized. ${ }^{18}$ As the prescription dose was the dose covering 95\% PTV, majority of patients received adequate radiation with whole group mean equal to $61.5 \mathrm{~Gy}$.

The salivary gland questionnaire with which we evaluated patients showed a decrease in the number of patients with grade 2 or worse xerostomia over a 12-month follow-up period (-Table 5). Overall comfort was poorest at 1 month postradiation. Most of the patients felt thirsty and had to carry water along with them. There was difficulty in speaking and disabled sleep in most of the patients but improved in few cases only. The patients in the whole group complained of decreased amount of saliva, though the number in the definitive radiation group increased between 6 and 9 months and decreased at 12 months. Similar results were seen with the change in taste, suggesting that taste depends on the saliva. These replies were in contrast with Amosson's study in which questions related to overall comfort, eating, and abnormal taste correlated significantly, and questions related to thirst, difficulty with sleep or speech, and the need to carry water daily did not correlate statistically with the dosimetric parameters of the parotid glands. ${ }^{16}$

The mean dose to the parotid glands is the most important parameter to assess for saliva production. ${ }^{16}$ The mean parotid thresholds of 24 and 26 Gy for unstimulated and stimulated flow rates, respectively, showed substantial preservation of the flow rates following RT and continued to improve over time for up to 12 months duration. ${ }^{19}$ The threshold doses known to cause xerostomia ranges from 26 to $39 \mathrm{~Gy}$, as reported by Chao and Eisbruch et al. ${ }^{1,2}$ Nearly every oncologist desires to achieve a mean dose of $\leq 26$ Gy to the parotid gland, as shown 
Table 3 Patients' characteristics

\begin{tabular}{|c|c|c|c|}
\hline Characteristics & Whole group, $N(\%)$ & Definitive RT, $N(\%)$ & Adjuvant RT, $N(\%)$ \\
\hline \multicolumn{4}{|l|}{ Age in years (range) } \\
\hline & $25-88$ & $25-88$ & $27-62$ \\
\hline \multicolumn{4}{|l|}{ Median age in years } \\
\hline$<60 y$ & $21(48.8)$ & $15(34.9)$ & $6(14.0)$ \\
\hline$>60 y$ & $22(51.2)$ & $18(41.9)$ & $4(9.3)$ \\
\hline \multicolumn{4}{|l|}{ Sex } \\
\hline Male & $33(76.7)$ & $26(60.5)$ & $7(16.3)$ \\
\hline Female & $10(23.3)$ & $7(16.3)$ & $3(7.0)$ \\
\hline \multicolumn{4}{|l|}{ Habits } \\
\hline No habits & $18(41.9)$ & $14(32.6)$ & $4(9.3)$ \\
\hline Tobacco & $13(30.2)$ & $11(25.6)$ & $2(4.7)$ \\
\hline Alcohol & $2(4.7)$ & 0 & $2(4.7)$ \\
\hline Both tobacco and alcohol & $10(23.3)$ & $8(18.6)$ & $2(4.7)$ \\
\hline \multicolumn{4}{|l|}{ Comorbidities } \\
\hline None & $28(65.1)$ & $20(46.5)$ & $8(18.6)$ \\
\hline Diabetes & $2(4.7)$ & $2(4.7)$ & 0 \\
\hline Hypertension & $8(18.6)$ & $7(16.3)$ & $1(2.3)$ \\
\hline $\begin{array}{l}\text { Both diabetes and } \\
\text { hypertension }\end{array}$ & $5(11.6)$ & $4(9.3)$ & $1(2.3)$ \\
\hline \multicolumn{4}{|l|}{ Complaints } \\
\hline Pain & $10(23.3)$ & $6(14.0)$ & $4(9.3)$ \\
\hline Ulcer & $7(16.3)$ & $4(9.3)$ & $3(7.0)$ \\
\hline Nodal mass & $9(20.9)$ & $9(20.9)$ & 0 \\
\hline Growth & $10(23.3)$ & $7(16.3)$ & $3(7.0)$ \\
\hline Change in voice & $4(9.3)$ & $4(9.3)$ & 0 \\
\hline Epistaxis & $3(7.0)$ & $3(7.0)$ & 0 \\
\hline \multicolumn{4}{|l|}{ Investigations } \\
\hline PET scan & $10(23.3)$ & $10(23.3)$ & 0 \\
\hline $\mathrm{CT}$ & $14(32.6)$ & $11(25.6)$ & $3(7.0)$ \\
\hline MRI & $30(69.8)$ & $23(53.5)$ & $7(16.3)$ \\
\hline \multicolumn{4}{|l|}{ Primary site } \\
\hline Oral cavity & $14(32.6)$ & $4(9.3)$ & $10(23.3)$ \\
\hline Oropharynx & $8(18.6)$ & $8(18.6)$ & 0 \\
\hline Hypopharynx & 8 (18.6) & $8(18.6)$ & 0 \\
\hline Nasopharynx & $3(7.0)$ & $3(7.0)$ & 0 \\
\hline Nasal sinuses & $3(7.0)$ & $3(7.0)$ & 0 \\
\hline Larynx & $4(9.3)$ & $4(9.3)$ & 0 \\
\hline MUO & $3(7.0)$ & $3(7.0)$ & 0 \\
\hline \multicolumn{4}{|l|}{ Histological diagnosis } \\
\hline Squamous & $42(97.67)$ & $32(74.42)$ & $10(23.25)$ \\
\hline Sinonasal & $1(2.33)$ & $1(2.33)$ & 0 \\
\hline \multicolumn{4}{|l|}{ Type of tumor } \\
\hline Infiltrative & $17(39.5)$ & $14(32.6)$ & $3(7.0)$ \\
\hline Proliferative & $16(37.2)$ & $12(27.9)$ & $4(9.3)$ \\
\hline Ulcerative & $10(23.3)$ & $7(16.3)$ & $3(7.0)$ \\
\hline
\end{tabular}


Table 3 (Continued)

\begin{tabular}{|c|c|c|c|}
\hline Characteristics & Whole group, $N(\%)$ & Definitive RT, $N(\%)$ & Adjuvant RT, $N(\%)$ \\
\hline \multicolumn{4}{|l|}{ T stage } \\
\hline $\mathrm{T} 1 / \mathrm{T} 2$ & $22(51.2)$ & $14(32.6)$ & $8(18.6)$ \\
\hline T3 & $9(20.9)$ & $8(18.6)$ & $1(2.3)$ \\
\hline T4 & $9(20.9)$ & $8(18.6)$ & $1(2.3)$ \\
\hline $\mathrm{Tx}$ & $3(7.0)$ & $3(7.0)$ & 0 \\
\hline \multicolumn{4}{|l|}{ N stage } \\
\hline No & $7(16.3)$ & $6(14.0)$ & $1(2.3)$ \\
\hline $\mathrm{N} 1$ & $12(27.9)$ & $7(16.3)$ & $5(11.6)$ \\
\hline N2 & $20(46.5)$ & $16(37.2)$ & $4(9.3)$ \\
\hline N3 & $1(2.3)$ & $1(2.3)$ & 0 \\
\hline $\mathrm{Nx}$ & $3(7.0)$ & $3(7.0)$ & 0 \\
\hline \multicolumn{4}{|l|}{ Stage } \\
\hline 2 & $5(11.6)$ & $4(9.3)$ & $1(2.33)$ \\
\hline 3 & $12(27.9)$ & $7(16.3)$ & $5(11.63)$ \\
\hline 4 & $23(53.5)$ & $19(44.2)$ & $4(9.3)$ \\
\hline Stage not available & $3(7.0)$ & $3(6.98)$ & 0 \\
\hline
\end{tabular}

Abbreviations: CT, computed tomography; MRI, magnetic resonance imaging; MUO, metastasis of unknown origin; PET, positron emission tomography; RT, radiotherapy.

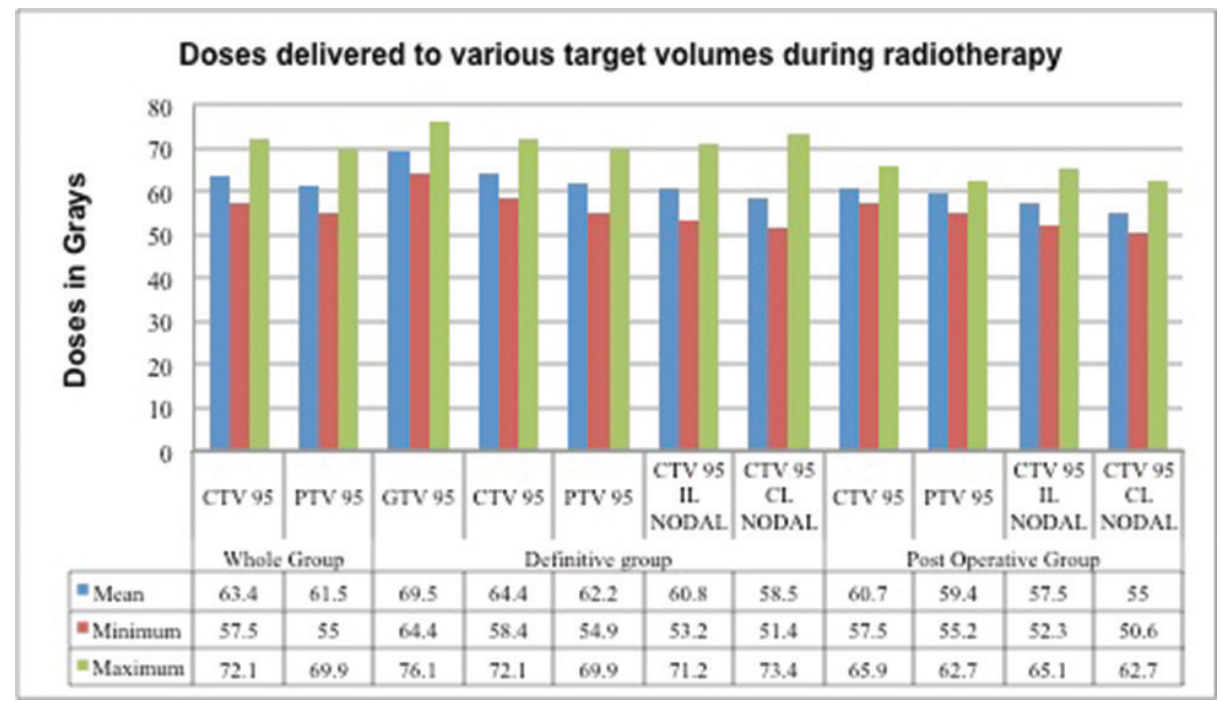

Fig. 1 Doses delivered to various target volumes during radiotherapy. CL, contralateral; CTV, clinical target volume; GTV, gross tumor volume; IL, ipsilateral; PTV, planning target volume.

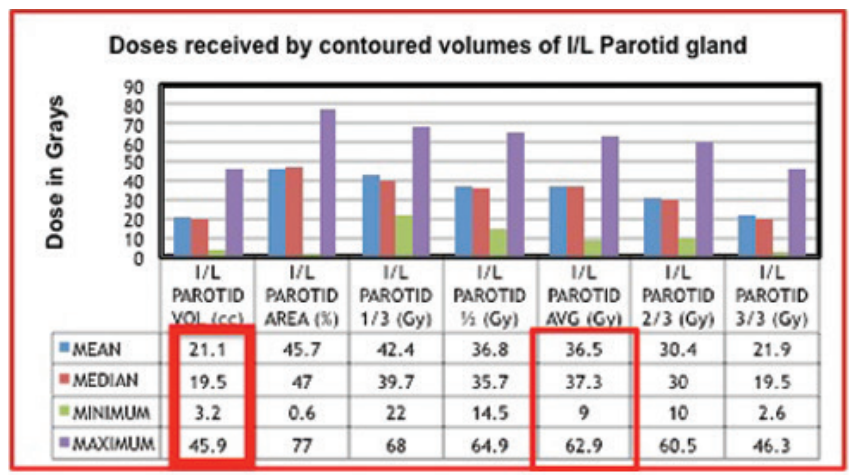

A

Fig. 2 Doses received by contoured volumes of I/L (A) and C/L (B) parotid glands. C/L, contralateral; I/L, ipsilateral.

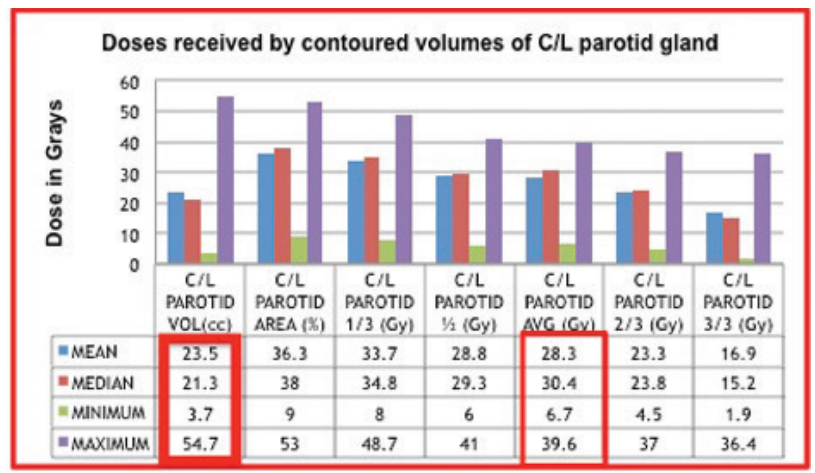

B 
Table 4 Correlation of volume of $\mathrm{I} / \mathrm{L}$ and $\mathrm{C} / \mathrm{L}$ parotid glands with grades of xerostomia

\begin{tabular}{|l|l|l|l|}
\hline $\begin{array}{l}\text { Ipsilateral parotid } \\
\text { gland volume vs. } \\
\text { grades of xerostomia }\end{array}$ & $N$ & Df & $p$-Value \\
\hline 3 mo & 34 & 58 & 0.343 \\
\hline 6 mo & 28 & 48 & 0.271 \\
\hline 9 mo & 27 & 48 & 0.438 \\
\hline 12 mo & 26 & 46 & 0.503 \\
\hline $\begin{array}{l}\text { Contralateral parotid } \\
\text { gland volume vs. } \\
\text { grades of xerostomia }\end{array}$ & $N$ & Df & $p$-Value \\
\hline 3 mo & 33 & 54 & 0.862 \\
\hline 6 mo & 28 & 48 & 0.892 \\
\hline 9 mo & 27 & 46 & 0.773 \\
\hline 12 mo & 25 & 44 & 0.523 \\
\hline
\end{tabular}

Abbreviations: Df, degrees of freedom; C/L, contralateral; I/L, ipsilateral.

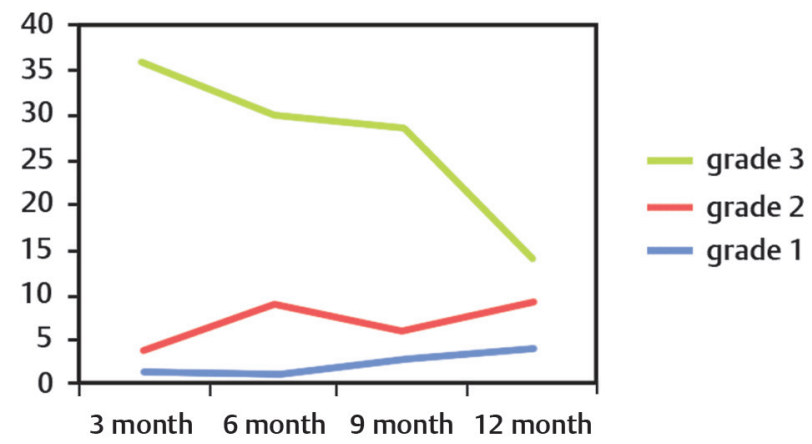

Fig. 3 Time trends in xerostomia: $\mathrm{X}$-axis shows the time (in months) $Y$-axis shows the number of patients.

Table 5 Percentages of patients with >grade 2 xerostomia at various months of follow-up

\begin{tabular}{|l|l|l|l|l|l|l|l|l|l|l|}
\hline \multirow{2}{*}{$\begin{array}{l}\text { Dose of radiation } \\
\text { vs. >grade 2 } \\
\text { xerostomia, } N \text { (\%) }\end{array}$} & \multicolumn{2}{|c|}{1 mo } & \multicolumn{2}{|c|}{3 mo } & \multicolumn{2}{c|}{6 mo } & \multicolumn{2}{c|}{9 mo } & \multicolumn{2}{c|}{12 mo } \\
\hline <30 Gy & $8(20)$ & $22(55)$ & $7(19.5)$ & $18(50)$ & $7(23.4)$ & $14(46.7)$ & $6(20.6)$ & $14(48.2)$ & $5(17.9)$ & $13(46.3)$ \\
\hline $30-40$ Gy & $17(42.5)$ & $18(45)$ & $14(38.9)$ & $17(47.3)$ & $10(33.3)$ & $15(50)$ & $9(31.0)$ & $12(41.3)$ & $8(28.6)$ & $11(39.3)$ \\
\hline$>40$ Gy & $15(37.5)$ & 0 & $14(38.9)$ & 0 & $12(40)$ & 0 & $11(37.9)$ & 0 & $11(39.2)$ & 0 \\
\hline
\end{tabular}

in a review of prospective phase 1 and 2 trials on parotid sparing RT. ${ }^{20}$ When we looked at these trials individually, Chao et al achieved an average parotid doses of $30.02 \pm 9.93 \mathrm{~Gy}$ (17.1570.27) in the definitive setting and $28.37 \pm 13.17$ Gy (1.9553.79) in the postoperative setting. ${ }^{7}$ Eisbruch et al achieved $\mathrm{I} / \mathrm{L}$ parotid mean dose of $55.2 \mathrm{~Gy}$ (standard deviation [SD]: 7.8) in the bilateral RT group and $48.2 \mathrm{~Gy}$ (SD: 14.5) in the unilateral RT group, and C/L parotid mean dose of $21.9 \mathrm{~Gy}$ (SD: 5.2) in the bilateral RT group and $4.1 \mathrm{~Gy}$ (SD: 2.8 ) in the unilateral RT group. ${ }^{21}$ Maes et al achieved a mean dose of 49 Gy (SD: 12) to the $\mathrm{I} / \mathrm{L}$ parotid gland and $21 \mathrm{~Gy}(\mathrm{SD}: 5$ ) to the $\mathrm{C} / \mathrm{L}$ parotid gland. ${ }^{9}$ Parliament et al achieved the averages of mean dose to each parotid gland as $29.6 \mathrm{~Gy}$ (right; 95\% confidence interval [CI]: 23.9-35.2) and $28.7 \mathrm{~Gy}$ (left; 95\% CI: 23.2-34.2). ${ }^{10}$ The average combined mean dose to parotid tissue was $30 \mathrm{~Gy}$ (95\% CI: 26.9-33.1). ${ }^{10}$ Blanco et al achieved mean doses of $31.7 \pm$ 18.3 and $34.1 \pm 19.2$ Gy to left and right parotid gland at 6 months after radiation therapy. ${ }^{22}$ Scrimger et al could achieve a mean dose of $18.4 \mathrm{~Gy}$ to the spared portion of the parotid glands, whereas the mean dose to parotid tissue was $27.1 \mathrm{~Gy} .{ }^{11}$ When we reviewed the Indian data, the average doses to I/Land C/Lglands were $44.1 \mathrm{~Gy}$ (SD: $12.5 ; 95 \% \mathrm{Cl}: 41.3-46.8 \mathrm{~Gy}$ ) and $31.5 \mathrm{~Gy}$ (SD: 6.5; 95\% CI: 30.2-32.9 Gy), respectively. ${ }^{23}$ Nutting et al were able to achieve a dose of $47.6 \mathrm{~Gy}$ to the I/L parotid gland and $25.4 \mathrm{~Gy}$ to the C/L parotid gland. ${ }^{24}$

In this study, we chose to apply same practical dose constraints as used by Amosson, that is, $35 \mathrm{~Gy}$ to the $\mathrm{I} / \mathrm{L}$ parotid gland and $25 \mathrm{~Gy}$ to the $\mathrm{C} / \mathrm{L}$ parotid gland. ${ }^{16}$ We were able to achieve mean doses of $36.8 \mathrm{~Gy}$ and $28.3 \mathrm{~Gy}$ to the I/L and C/L parotid glands, respectively. These values compared well with other authors, suggesting that even with large tumors, it was possible to achieve the prescribed dose constraints. ${ }^{24}$ However, there was no direct correlation between the mean dose received by both $\mathrm{I} / \mathrm{L}$ and $\mathrm{C} / \mathrm{L}$ parotid glands and the grades of xerostomia at $1,3,6,9$, and 12 months postradiation. This stood contrary to Amosson's study but matched well with Nishimura et al. ${ }^{16,25}$ When we looked into the reasons why these data showed clinical insignificance, we realized that xerostomia starts even when few grays of radiation are delivered. The parotids could not be spared from higher doses due to lymph nodal positivity in the upper deep cervical region (most of them being N2 or N2c) or tumors lying in adjacent region (naso-oropharynx). Majority of patients selected by various other scientists were of N0 or N1 stage. ${ }^{16}$ The other reason for insignificance was that a small number of patients receiving higher doses were selected for the study. An effort to keep the dose to at least the C/L parotid gland to $\leq 26$ Gy was even difficult. Both parotid glands received a mean dose of $>26 \mathrm{~Gy}$. The salivary function in each gland appeared to be lost exponentially at a rate of approximately $5 \%$ per $1 \mathrm{~Gy}$ of mean dose. ${ }^{22}$ We did not compromise local control in preference to achieving mean dose to parotids. The addition of chemotherapy in more than $75 \%$ cases in this study also seems contributory to xerostomia.

The absolute volume of the parotid glands likely reflects reserve saliva output and predicts xerostomia in 
parotid-sparing IMRT. The absolute volume of the $\mathrm{I} / \mathrm{L}$ and $\mathrm{C} / \mathrm{L}$ parotid glands in this study was between 3.2 and $45.9 \mathrm{~mL}$ $($ mean $=21.1 \mathrm{~mL})$ and 3.7 and $54.7 \mathrm{~mL}($ mean $=23.5 \mathrm{~mL})$, respectively. Since this was a randomized nonbiased study, and the patient with smallest volume of parotid was most compliant, she was included. The study did not show a direct statistical correlation between grades and initial volume of the parotid glands. This contrasted with the findings of Nishimura et al who showed a significant correlation between the initial volume of the parotid glands and the grades of xerostomia. ${ }^{25}$ Parotid gland in his study was recontoured in the boost phase of treatment, whereas we did it only once before starting external beam RT. ${ }^{25}$ During the course of IMRT, the volume of the parotid glands decreases significantly. ${ }^{26}$ The parotid glands decrease in volume $(0.6 \%$ per day of initial volume) and shift medially. ${ }^{26}$ We maintained a good nutritional status of the patient so that shrinkage of parotid could be avoided. Wherever required, Freka's nasogastric or percutaneous endoscopic gastrostomy tube insertion was performed. During the study, we realized that parotids need to be recontoured in the fifth week of treatment. We are further evaluating changes in volume and xerostomia scores by adaptive RT in our institution.

The partial volume thresholds as given by Eisbruch et al were 67,45 , and $24 \%$ gland volume receiving more than 15 , 30 , and $45 \mathrm{~Gy}$, respectively. ${ }^{19}$ We calculated doses received by partial volumes of the parotid glands. The I/L parotid $1 / 3$, $1 / 2$, and $2 / 3$ volume received a mean dose of $42.4 \mathrm{~Gy}$ (range: 22-68 Gy), 36.8 Gy (range: 14.5-64.9 Gy), and 30.4 Gy (range: 10.0-60.5 Gy), respectively. The $\mathrm{C} / \mathrm{L}$ parotid $1 / 3,1 / 2$, and $2 / 3$ volume received a mean dose of $33.7 \mathrm{~Gy}$ (range: 8.0-48.7 Gy), 28.8 Gy (range: 6-41 Gy), and 23.3 Gy (range: $4.5-37 \mathrm{~Gy}$ ), respectively. Even the partial volume thresholds were statistically insignificant. The full $(3 / 3)$ volume of the $\mathrm{I} / \mathrm{L}$ and $\mathrm{C} / \mathrm{L}$ parotid glands received a median dose of 19.5 Gy (range: 2.6-46.3 Gy) and 15.2 Gy (range: 1.9-36.4 Gy), respectively. Thus, it is difficult in locally advanced tumors to volumetrically spare the parotid gland especially if the disease or lymph node is lying ipsilaterally. It is said that more than $50 \%$ of the parotid glands have to be outside the radiation field to prevent severe dryness; irradiation of submandibular and sublingual glands had only a minor effect. ${ }^{27}$ However, we included patients in whom parotids were lying in radiation portals.

The parotid salivary function continues to improve between 6 and 12 months after radiation, as shown by Blanco et al. ${ }^{22} \mathrm{~A}$ phase 3 multicenter randomized controlled trial (PARSPORT) compared patients treated with IMRT with those treated with conventional radiation. At 12 and 24 months, grade 2 or worse xerostomia was significantly lower in the IMRT group; there was significant recovery in saliva secretion and clinically significant improvements in dry-mouth-specific and global QOL scores. ${ }^{24}$ Similarly, in our study, recovery in grade 2 or worse xerostomia score was significantly evident around 9 months postradiation, suggesting that maximum recovery occurred within this time period (-Table 5).

\section{Conclusion}

There is no direct statistically significant correlation between the DVH of the parotid glands and the grades of xerostomia, although statistically evident recovery in grades was seen at 9 months. The study assumed significance when a small number of locoregionally advanced cases of head and neck cancer were selected for the study. The results might appear contrary to the well-established beliefs; in a parallel organ such as parotid, the severity and grades of xerostomia are inversely proportional to the amount of parotid spared by radiation.

We also felt that the change in dosimetric parameters for parotid gland might not be sufficiently accurate when only preradiation CT scan was used for planning. ${ }^{28}$ As GTV decreased significantly during fractionated RT, serial imaging and sequential IMRT boost planning might be necessary. Sequential IMRT boost might adequately spare the parotid gland, thereby reducing the mean dose, but it was an expensive and time-consuming strategy. ${ }^{29}$

Based on our observations, we acknowledged the following few facts:

- Xerostomia gets aggravated because of a complex interplay of subjective, objective, and psychosocial factors.

- Subjective questionnaires assessed xerostomia better.

- IMRT in head and neck can be exploited to decrease parotid dose but not at the cost of good local control.

- Adaptive RT offers some practical solution.

The study had its limitation in the form of delay in publication. The data were variously assessed for its importance. This was conducted at a time when IMRT was gaining strong foothold in an established tertiary care center.

\section{Funding}

None.

\section{Note}

This study was presented as oral paper presentation in Consultant Paper Category in Larynx/Hypopharynx at the Multidisciplinary perspectives (Forum V): First National Workshop in Head and Neck Salvage, Patel Hospital, Jalandhar, Punjab, March 17, 2018.

\section{Conflict of Interest}

None declared.

\section{Acknowledgments}

This paper is the result of persistent efforts and constant learning. I thank the almighty, my family, senior colleagues, and my patients. The authors also acknowledge the contributions of Mr. N. Manoharan for statistical analysis, Prof. Sushmita Ghoshal for accepting to be an independent referee, and Dr. A. K. Anand for providing this topic as thesis.

\section{References}

1 Chao KS. Protection of salivary function by intensity-modulated radiation therapy in patients with head and neck cancer. Semin Radiat Oncol 2002;12(1, Suppl 1) :20-25 
2 Eisbruch A, Ship JA, Kim HM. Ten Haken RK. Partial irradiation of the parotid gland. Semin Radiat Oncol 2001;11(3):234-239

3 Franzén L, Funegård U, Ericson T, Henriksson R. Parotid gland function during and following radiotherapy of malignancies in the head and neck. A consecutive study of salivary flow and patient discomfort. Eur J Cancer 1992;28(2-3):457-462

4 Lin A, Kim HM, Terrell JE, Dawson LA, Ship JA, Eisbruch A. Quality of life after parotid-sparing IMRT for head-and-neck cancer: a prospective longitudinal study. Int J Radiat Oncol Biol Phys 2003;57(1):61-70

5 Mossman KL. Quantitative radiation dose-response relationships for normal tissues in man. II. Response of the salivary glands during radiotherapy. Radiat Res 1983;95(2):392-398

6 Chao KS, Majhail N, Huang CJ, et al. Intensity-modulated radiation therapy reduces late salivary toxicity without compromising tumor control in patients with oropharyngeal carcinoma: a comparison with conventional techniques. Radiother Oncol 2001;61(3):275-280

7 Chao KS, Deasy JO, Markman J, et al. A prospective study of salivary function sparing in patients with head-and-neck cancers receiving intensity-modulated or three-dimensional radiation therapy: initial results. Int J Radiat Oncol Biol Phys 2001;49(4):907-916

8 Lee $\mathrm{N}$, Xia P, Quivey JM, et al. Intensity-modulated radiotherapy in the treatment of nasopharyngeal carcinoma: an update of the UCSF experience. Int J Radiat Oncol Biol Phys 2002;53(1):12-22

9 Maes A, Weltens C, Flamen P, et al. Preservation of parotid function with uncomplicated conformal radiotherapy. Radiother Oncol 2002;63(2):203-211

10 Parliament MB, Scrimger RA, Anderson SG, et al. Preservation of oral health-related quality of life and salivary flow rates after inverse-planned intensity- modulated radiotherapy (IMRT) for head-and-neck cancer. Int J Radiat Oncol Biol Phys 2004;58(3):663-673

11 Scrimger R, Kanji A, Parliament M, et al. Correlation between saliva production and quality of life measurements in head and neck cancer patients treated with intensity-modulated radiotherapy. Am J Clin Oncol 2007;30(3):271-277

12 Kam MK, Leung SF, Zee B, et al. Prospective randomized study of intensity-modulated radiotherapy on salivary gland function in early-stage nasopharyngeal carcinoma patients. J Clin Oncol 2007;25(31):4873-4879

13 Jabbari S, Kim HM, Feng M, et al. Matched case-control study of quality of life and xerostomia after intensity-modulated radiotherapy or standard radiotherapy for head-and-neck cancer: initial report. Int J Radiat Oncol Biol Phys 2005;63(3):725-731

14 Eisbruch A, Foote RL, O'Sullivan B, Beitler JJ, Vikram B. Intensity-modulated radiation therapy for head and neck cancer: emphasis on the selection and delineation of the targets. Semin Radiat Oncol 2002;12(3):238-249

15 Grégoire V, Levendag P, Ang KK, et al. CT-based delineation of lymph node levels and related CTVs in the node-negative neck: DAHANCA, EORTC, GORTEC, NCIC,RTOG consensus guidelines. Radiother Oncol 2003;69(3):227-236
16 Amosson CM, Teh BS, Van TJ, et al. Dosimetric predictors of xerostomia for head-and-neck cancer patients treated with the smart (simultaneous modulated accelerated radiation therapy) boost technique. Int J Radiat Oncol Biol Phys 2003;56(1):136-144

17 Eisbruch A, Rhodus N, Rosenthal D, et al. How should we measure and report radiotherapy-induced xerostomia? Semin Radiat Oncol 2003;13(3):226-234

18 Bortfeld T, Schmidt-Ullrich R, De Neve W, Wazer DE, eds Image-Guided IMRT. Berlin: Springer; 2006

19 Eisbruch A, Ten Haken RK, Kim HM, Marsh LH, Ship JA. Dose, volume, and function relationships in parotid salivary glands following conformal and intensity-modulated irradiation of head and neck cancer. Int J Radiat Oncol Biol Phys 1999;45(3):577-587

20 Dirix P, Nuyts S. Evidence-based organ-sparing radiotherapy in head and neck cancer. Lancet Oncol 2010;11(1):85-91

21 Eisbruch A, Kim HM, Terrell JE, Marsh LH, Dawson LA, Ship JA. Xerostomia and its predictors following parotid-sparing irradiation of head-and-neck cancer. Int J Radiat Oncol Biol Phys 2001;50(3):695-704

22 Blanco AI, Chao KS, El Naqa I, et al. Dose-volume modeling of salivary function in patients with head-and-neck cancer receiving radiotherapy. Int $\mathrm{J}$ Radiat Oncol Biol Phys 2005;62(4):1055-1069

23 Nangia S, Chufal KS, Tyagi A, Bhatnagar A, Mishra M, Ghosh D. Selective nodal irradiation for head and neck cancer using intensity-modulated radiotherapy: application of RTOC consensus guidelines in routine clinical practice. Int J Radiat Oncol Biol Phys 2010;76(1):146-153, 201

24 Nutting CM, Morden JP, Harrington KJ, et al; PARSPORT trial management group. Parotid-sparing intensity modulated versus conventional radiotherapy in head and neck cancer (PARSPORT): a phase 3 multicentre randomised controlled trial. Lancet Oncol 2011;12(2):127-136

25 Nishimura Y, Nakamatsu K, Shibata T, et al. Importance of the initial volume of parotid glands in xerostomia for patients with head and neck cancers treated with IMRT. Jpn J Clin Oncol 2005;35(7):375-379

26 Barker JL Jr, Garden AS, Ang KK, et al. Quantification of volumetric and geometric changes occurring during fractionated radiotherapy for head-and-neck cancer using an integrated CT/linear accelerator system. Int J Radiat Oncol Biol Phys 2004;59(4):960-970

27 Mira JG, Wescott WB, Starcke EN, Shannon IL. Some factors influencing salivary function when treating with radiotherapy. Int J Radiat Oncol Biol Phys 1981;7(4):535-541

28 Eneroth CM, Henrikson CO, Jakobsson PA. Pre-irradiation qualities of a parotid gland predicting the grade of functional disturbance by radiotherapy. Acta Otolaryngol 1972;74(6):436-444

29 Dogan N, King S, Emami B, et al. Assessment of different IMRT boost delivery methods on target coverage and normal-tissue sparing. Int J Radiat Oncol Biol Phys 2003;57(5):1480-1491 